\title{
Cryopreservation enables long-term conservation of critically endangered species Rubus humulifolius
}

\author{
Jaanika Edesi ${ }^{1,2}$ (D) . Jonne Tolonen ${ }^{1} \cdot$ Anna Liisa Ruotsalainen ${ }^{1}$ (D) . Jouni Aspi ${ }^{1}$ (D) . \\ Hely Häggman ${ }^{1}$ (D)
}

Received: 31 December 2018 / Revised: 7 October 2019 / Accepted: 14 October 2019 /

Published online: 13 November 2019

(c) The Author(s) 2019

\begin{abstract}
Ex situ storage plays an important role in the conservation of plant biodiversity. Cryopreservation at ultra-low temperatures $\left(-196^{\circ} \mathrm{C}\right)$ is the only long-term ex situ preservation method for plant species that cannot be stored in seed banks. In the present study, we developed a cryopreservation protocol for micropropagated Rubus humulifolius (Rosaceae) plants representing currently critically endangered population of the species in Finland. Abscisic acid (ABA) has been found to increase the freezing tolerance of several plant species. Thus, we studied the effect of a 10-day pretreatment with 0,2 or $4 \mathrm{mg} / \mathrm{l} \mathrm{ABA}$ in comparison to freshly dissected buds. We also studied how the duration of in vitro subculture affects cryopreservation result. The ABA pretreatment had divergent effect on control and cryopreserved buds: the regeneration of non-cryopreserved control buds increased from $51 \%$ to $70 \%, 90 \%$ or $87 \%$ while the regeneration of cryopreserved buds decreased from $52 \%$ to $35 \%, 6 \%$ or $9 \%$ after 0,2 or $4 \mathrm{mg} / \mathrm{l} \mathrm{ABA}$ pre-treatments, respectively. Buds from plants subcultured for 1 month had $63 \%$ survival, which, however, decreased to $29 \%$ or nil $\%$ after 2 or 4 months subculture. The regenerated plants were successfully transferred from in vitro to in vivo conditions in common garden. Growing in garden is needed for future restoration of the species in wild. Cryostorage and other ex situ conservation actions carried out in botanical gardens may be of increasing importance as a tool to maintain plant biodiversity in the future.
\end{abstract}

Keywords In vitro cultivation $\cdot$ Abscisic acid $\cdot$ Threatened plant species $\cdot$ Ex situ conservation

Communicated by David L Hawksworth.

This article belongs to the Topical Collection: Ex situ conservation.

Jaanika Edesi

jaanika.edesi@luke.fi

1 Ecology and Genetics Unit, University of Oulu, P.O. Box 3000, 90014 Oulu, Finland

2 Present Address: Production Systems, Natural Resources Institute (Luke), 57200 Savonlinna, Finland 


$\begin{array}{ll}\text { Abbreviations } \\ \text { ABA } & \text { Abscisic acid } \\ \text { PVS2 } & \text { Plant vitrification solution 2 } \\ \text { DMSO } & \text { Dimethyl sulfoxide } \\ \text { LN } & \text { Liquid nitrogen }\end{array}$

\section{Introduction}

The trends observed in the loss of plant biodiversity over the last 100 years have been a matter of great concern (Heywood and Dulloo 2005; Hooper et al. 2012; Vellend et al. 2017). Conversion of primary vegetation to agriculture, climate change combined with habitat loss and fragmentation are the main key factors affecting biodiversity and to cause species to become extinct (Thomas et al. 2004; Mantyka-Pringle et al. 2012; Vellend et al. 2017). The situation today is still very alarming, despite the efforts made to conserve plant diversity. It has been shown that increase in global temperature will increase the species turnover rate and decrease the mean stable area of species in all biomes (Alkemade et al. 2011). Changes in mean climate variables and greater risks of extreme weather, including prolonged drought and storms, are events that biomes will have to adapt to (Lindner et al. 2010). Climate change has also known to be related to the observed northward and uphill distribution shifts of many European plant species (Feehan et al. 2009). Changing climate will cause a myriad of changes, and therefore, different kinds of conservation strategies related to in situ or ex situ maintenance of plant populations need to be applied. From these, in situ conservation, preservation of threatened plant population in the original environment is no doubt of highest priority (Hannah et al. 2002). However, in situ conservation is suitable mainly for the species and populations that can be preserved in the original environment of the species, e.g. in protected areas in natural reserves and conservation corridors. In a situation, where in situ conservation is not possible, ex situ conservation i.e. conservation outside the original environment-is the method of choice. Furthermore, ex situ conservation is applicable as an additional conservation method to in situ method working as a backup collection for the most vulnerable material (Li and Pritchard 2009; Hawkes et al. 2012). For example, clonal field repositories, botanical gardens, seed banks and in vitro collections are widely applied for both economically important and endangered plant species. Thus, ex situ conservation is applied as an additional measure to supplement in situ conservation. The Target 8 of the Global Strategy for Plant Conservation (agreed at the CBD meeting in Nagoya in 2010) is the ex situ conservation of at least $75 \%$ of threatened plant species, with at least $20 \%$ available for recovery and restoration programs (https ://www.cbd.int/gspc/targets.shtml).

Cryopreservation process and methods allow long-term survival of organisms at liquidnitrogen $(\mathrm{LN})$ temperatures $\left(-196^{\circ} \mathrm{C}\right)$. In $\mathrm{LN}$-storage, one of the benefits is the long-term deferment of regeneration costs. Although no biological sample is immortal, the specimens in LN storage will have indefinite lifespans ( $\mathrm{Li}$ and Pritchard 2009). Cryopreservation is the only ex situ conservation method for long-term preservation of species that cannot be stored in seed banks, e.g. clonal crops or species with a low number or recalcitrant seeds. Moreover, requiring only a minimum space and maintenance efforts, cryopreservation has turned out to be a very important tool for the long-term storage of plant genetic material (Engelmann 2004; Matsumoto 2017). 
The most commonly used cryopreservation techniques are vitrification, encapsulation dehydration, controlled rate cooling, and dormant bud preservation (Benson 2008; Benelli et al. 2013; Jenderek and Reed 2017). Vitrification is a physical process where solution solidifies into a metastable glass at very low temperatures and avoids crystallisation (Sakai et al. 2008). Many plant vitrification protocols use two main techniques: the addition of cryoprotective additives at very high concentrations and the removal of water by evaporative desiccation and osmotic dehydration. A cryoprotectant acts as an antifreeze substance and must be non-toxic to the cell at the concentration that is required for it to be effective (Benson 2008).

More than 200 plant species, also including a few species from genus Rubus, Rosaceae, have been successfully cryopreserved using the PVS-based vitrification protocol (Reed 2008; Matsumoto and Niino 2014). For example, Gupta and Reed (2006) cryopreserved shoot tips of four genotypes representing three Rubus species (R. ursi$n u s, R$. crataegifolius and Rubus hybrid cv. Chehalem) successfully with a PVS2-based vitrification method. The four genotypes showed $71 \%$ average regrowth after cryopreservation. In particular, the vitrification and encapsulation-dehydration methods have been continuously developed and are thus the most frequently employed methods for cryopreservation of clonally propagated plant species. Genus Rubus, with around 500 species, is one of the most diverse plant genera (Skirvin et al. 2005). R. humulifolius is a rhizome-forming perennial plant, found in northern areas of Eurasia from the Lake Onega to the coast of the Pacific Ocean. A separate population of the species was found native in Finland in the beginning of the twenteeth century in the Jyväskylä area (Mikkola 1927). Because of human activity, the natural population disappeared in 1957 (Kypärä 2012). Reintroductions with the same plant material were carried out but with no long-term success. In 1986, a micropropagation project was initiated and a successful reintroduction into the wild in Jyväskylä in a nature conservation area was carried out (Kypärä 2012). Despite the presence of this reintroduced population, $R$. humulifolius has been classified as regionally extinct (RE) (Rassi et al. 2010) and more recently as critically endangered (CR) (Hyvärinen et al. 2019) in Finland.

Rubus humulifolius plants from the Jyväskylä population have been maintained in vitro in the Botanical Garden of the University of Oulu since 2006 (20 plantlets all presenting one $R$. humulifolius clone). More recently, $R$. humulifolius was included as a target species into the EU Life+ project Ex Situ Conservation of Finnish Native Plant Species (ESCAPE) project (LIFE+ 2011 BIO/FI/917 ESCAPE; https://luomus.fi/en/ exsitu-conservation-finnish-native-plant-species). During this project, we developed the cryopreservation protocol for $R$. humulifolius to enable a long-term conservation of the germplasm of the separate populations of the species.

\section{Materials and methods}

\section{Plant material}

In vitro cultures of micropropagated $R$. humulifolius $C$. A. Mey plants maintained at the Biotechnology Laboratory of Botanical Gardens at the University of Oulu were used as explant material for the present study. The plant material was originally received from Natural Resource Institute, Finland where the micropropagation protocol 
was developed in order to restore the species representing the most western habitat of $R$. humulifolius (Kypärämäki, Jyväskylä, Finland ETRS-TM35FIN: N 6901644, E 432210).

\section{In vitro cultivation}

The in vitro cultivation/maintenance of $R$. humulifolius plants was carried out on $1 / 2 \mathrm{MS}$ (Murashige and Skoog 1962) medium with $0.1 \mathrm{mg} / \mathrm{l} \mathrm{BAP,} 0.05 \mathrm{mg} / \mathrm{l} \mathrm{NAA}, 100 \mathrm{mg} / \mathrm{l} \mathrm{myo-}$ inositol, $30 \mathrm{~g} / \mathrm{l}$ sucrose and $7.6 \mathrm{~g} / \mathrm{l}$ agar at $22{ }^{\circ} \mathrm{C}$ under $16 / 8$ photoperiod. The illumination was provided by fluorescent tubes (Osram L $30 \mathrm{~W} / 830$ ) with intensity of 107-128 $\mu \mathrm{mol} /$ $\mathrm{m}^{2} / \mathrm{s}$. The plants were transferred to the fresh medium at 3-month interval.

\section{Cryopreservation protocol}

For cryopreservation of $R$. humulifolius, a droplet vitrification method was used. In the present study, cryopreservation was done like in encapsulation vitrification protocol originally developed for raspberry (Rubus idaeus) but without encapsulation step (Wang et al. 2005). We studied the effect of a 10-day pretreatment with or without abscisic acid (0, 2, or $4 \mathrm{mg} / \mathrm{l} \mathrm{ABA}$ ) performed on 1-month-old buds dissected from multiple shoots of in vitro plants. For control, the cryopreservation protocol (see below) was applied immediately after dissection (Treatment 1 in Table 2). We studied also the effect of propagation interval on the cryopreservation success of $R$. humulifolius. The buds were collected from 1-, 2- or 4-months-old donor plants (from last subculture), later referred as in vitro age. All experiments/treatments included non-cryopreserved control buds (treated like cryopreserved ones but without freezing in $\mathrm{LN}$ ) and all the work steps during cryopreservation procedure were done aseptically. The buds in each treatment had three replicates (three Petri plates/ treatment) and the experiment was done once.

For cryopreservation, the buds (2-4 mm size) either with or without pre-treatment were first precultured on $1 / 2 \mathrm{MS}$ medium with $0.1 \mathrm{mg} / \mathrm{l} \mathrm{BAP,} 0.05 \mathrm{mg} / \mathrm{l} \mathrm{NAA}, 100 \mathrm{mg} / \mathrm{l} \mathrm{myo-ino-}$ sitol including $0.25,0.5$ and $0.75 \mathrm{M}$ sucrose for one day per concentration (Fig. 1a). After that, the buds were transferred into the loading solution $(0.75 \mathrm{M}$ sucrose, $2 \mathrm{M}$ glycerol, $1 / 2$ MS) for $90 \mathrm{~min}$. Thereafter, the buds were vitrified in plant vitrification solution 2 (PVS2: $30 \%$ glycerol, $15 \%$ ethylene glycol, 15\% DMSO, 0.4 M sucrose in $1 / 2 \mathrm{MS}$ ) for $3 \mathrm{~h}$. Incubations in loading solution and PVS2 were carried out by placing the buds on small Petri plates moistened with $2 \mathrm{ml}$ of each solution at a time. Preculture, loading and vitrification steps were performed at room temperature (RT). After cryoprotection in PVS2, aluminum foil pieces $(0.5 \times 1.5 \mathrm{~cm})$ were prepared with $2-3 \mu \mathrm{l}$ droplets of PVS2 (Fig. 1b) and the buds were transferred to the droplets ( 5 per foil) and cryopreserved by transferring the foils quickly into cryotubes filled with liquid nitrogen (LN) for at least $1 \mathrm{~h}$.

\section{Recovery after cryopreservation}

The first step in recovery of cryopreserved $R$. humulifolius buds was thawing the cryotubes at $40{ }^{\circ} \mathrm{C}$ water bath for $3 \mathrm{~min}$. Thereafter, the cryotubes were opened and foils with buds transferred to $30 \mathrm{ml}$ unloading solution (1 M sucrose in $1 / 2 \mathrm{MS}$ ) at RT. After that, the excess moisture was removed by transfer to filter paper and the buds were cultivated on $1 / 2$ MS medium with $0.1 \mathrm{mg} / 1$ BAP, $0.05 \mathrm{mg} / \mathrm{l} \mathrm{NAA,} 100 \mathrm{mg} / \mathrm{l}$ myo-inositol and $30 \mathrm{~g} / \mathrm{l}$ 

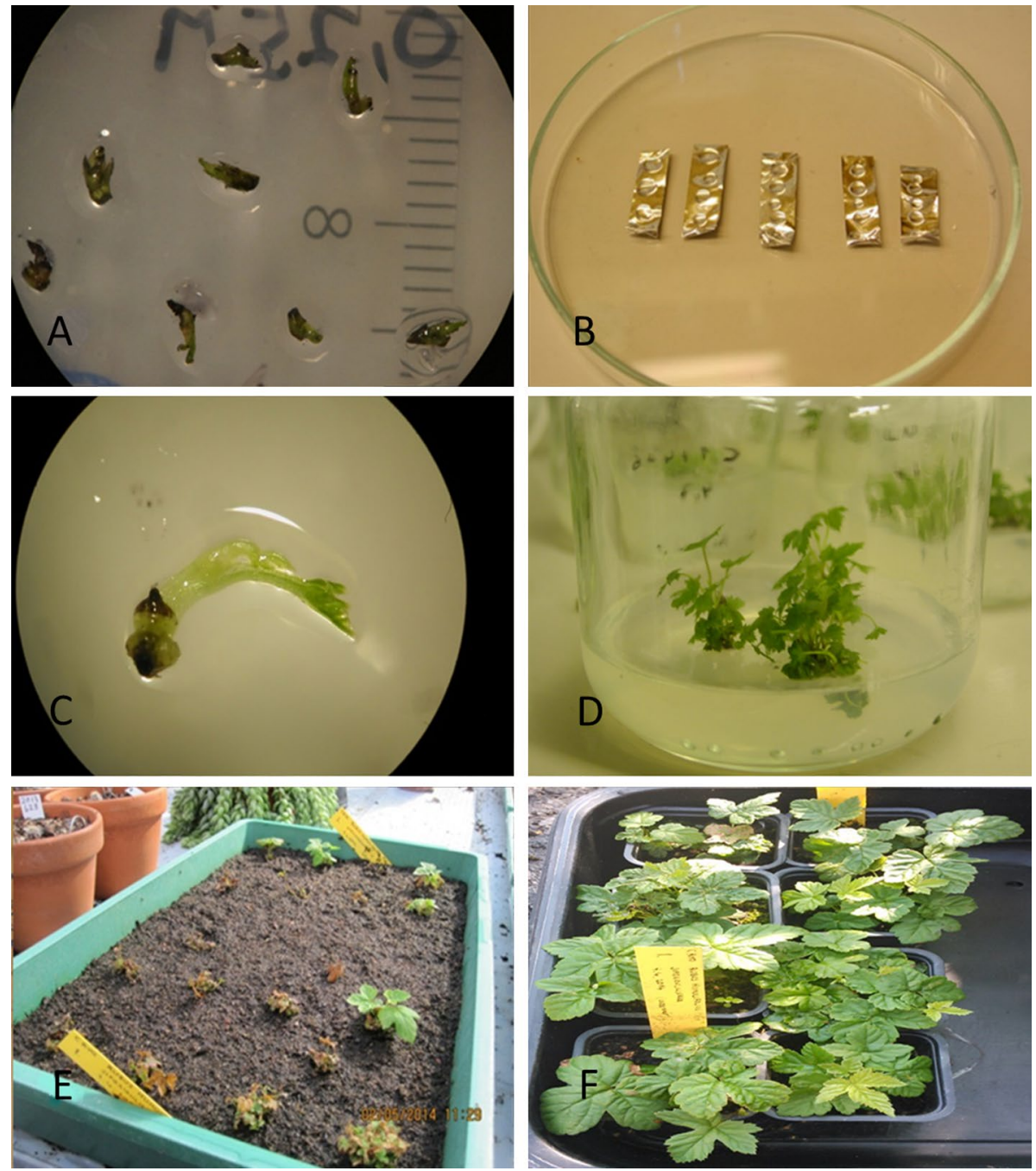

Fig. 1 a. Rubus humulifolius buds after sucrose treatment. b. Foil strips with PVS2 droplets. c. Regenerating bud 2 weeks after cryopreservation. d. Cryopreserved material 2 months after cryopreservation. e. Cryopreserved material 2 weeks after transfer to ex vitro conditions. f. Cryopreserved overwintered $R$. humulifolius plants

sucrose in Petri plates for 4 days in dark before transferring to light in the culture room. Survival (S) and regeneration (R) of buds were estimated at several time points (between 1 and 5 weeks) under stereomicroscope. Buds classified as survived ones (S) included both regenerating buds (R) i.e. buds forming new shoots (Fig. 1c) and buds which were alive but not regenerating. 


\section{Transfer of cryopreserved material into ex vitro conditions}

Approximately 4 weeks after thawing the cryopreserved buds started to produce shoots which were transferred into larger tissue-culture jars containing $1 / 2 \mathrm{MS}$ medium with $0.1 \mathrm{mg} / \mathrm{l} \mathrm{BAP,} 0.05 \mathrm{mg} / \mathrm{l} \mathrm{NAA}$ and $100 \mathrm{mg} / \mathrm{l}$ myo-inositol (Fig. 1d). After a few months, the shoots started to produce roots either with or without $0.1 \mathrm{mg} / \mathrm{l}$ indole-3-butyric acid (IBA) treatment. Altogether 19 rooted shoots were transferred, from in vitro to in vivo conditions (Fig. 1e). During the first weeks in vivo, high moisture atmosphere was maintained. The plants were let to overwinter in an unheated greenhouse (temperature maintained above $0{ }^{\circ} \mathrm{C}$ at the Botanical Gardens of the University of Oulu).

\section{Statistical analysis}

A Chi square test of independence was performed for both survival and regeneration results for cryopreserved and control buds. If the $p$ value was $<0.05$, the result was not independent of the treatment and pairwise comparisons by Chi square test of equal proportions with Holm correction were carried out. The statistical program R (R Core Team 2012) was used to perform the statistical analyses.

\section{Results}

The in vitro material of $R$. humulifolius was successfully cryopreserved by droplet vitrification method. The highest survival (62.0) and regeneration (52.0) percentages of cryopreserved buds were obtained from 1-month-old buds without any pretreatment (Tables 1, 2). Longer period from the last in vitro subculture had negative effect on post-cryopreservation survival as only $29.4 \%$, representing the buds derived from 2-months-old donor plants survived, but no survival was observed when the buds were dissected from 4-months-old donor plants (Table 1).

For control buds (no cryopreservation, no pretreatment) the survival percentages were 73.3\% for buds originating from 1-month-old donor plants whereas the corresponding survival percentages for 2- and 4-months-old donor plants were $60.0 \%$ and $50.0 \%$, respectively (Table 1). Accordingly, survival percentage of control buds (no cryopreservation, no pretreatment) derived from 1-month-old donor plants was $61.2 \%$.

Table 1 The effect of in vitro age on $R$. humulifolius postcryopreservation survival (S) and regeneration $(\mathrm{R})$ percentage $(\%)$

\begin{tabular}{lrllllll}
\hline In vitro age & \multicolumn{2}{l}{$\mathrm{LN}$} & & & \multicolumn{2}{l}{$\mathrm{LN}$} \\
\cline { 2 - 4 } \cline { 6 - 8 } & $\mathrm{n}$ & $\mathrm{S}(\%)$ & $\mathrm{R}(\%)$ & & $\mathrm{n}$ & $\mathrm{S}(\%)$ & $\mathrm{R}(\%)$ \\
\hline 1 & 30 & 73.3 & 66.6 & & 105 & 62.8 & 48.6 \\
2 & 5 & 60.0 & na & & 17 & 29.4 & na \\
4 & 4 & 50.0 & na & & 8 & 0.0 & na \\
\hline
\end{tabular}

+LN, cryopreserved, -LN, non-cryopreserved control. In vitro age, time from last subculture (months)

$n$ the number of buds in each treatment, $n a$ not available 
Table 2 The effect of a 10-day ABA pre-treatment on post-cryopreservation survival (S) and regeneration (R) percentages (\%) of $R$. humulifolius

\begin{tabular}{|c|c|c|c|c|c|c|c|}
\hline \multirow[t]{2}{*}{ Treatment no. } & \multirow[t]{2}{*}{ Pre-treatment } & \multicolumn{3}{|c|}{$-\mathrm{LN}$} & \multicolumn{3}{|c|}{$+\mathrm{LN}$} \\
\hline & & $\mathrm{n}$ & $\mathrm{S}(\%)$ & $\mathrm{R}(\%)$ & $\mathrm{n}$ & $\mathrm{S}(\%)$ & $\mathrm{R}(\%)$ \\
\hline 1 & - & 49 & $61.2 \mathrm{a}$ & $51.0 \mathrm{a}$ & 50 & $62.0 \mathrm{a}$ & $52.0 \mathrm{a}$ \\
\hline 2 & $0 \mathrm{mg} / \mathrm{l} \mathrm{ABA}$ & 33 & $84.8 \mathrm{ac}$ & $75.8 \mathrm{ac}$ & 34 & $47.1 \mathrm{ac}^{*}$ & $35.3 \mathrm{ac}^{*}$ \\
\hline 3 & $2 \mathrm{mg} / \mathrm{ABA}$ & 31 & $93.5 \mathrm{bc}^{*}$ & $90.3 \mathrm{bc}^{* *}$ & 34 & $17.6 b^{* *}$ & $5.9 \mathrm{~b}^{* *}$ \\
\hline \multirow[t]{3}{*}{4} & $4 \mathrm{mg} / \mathrm{ABA}$ & 31 & $96.8 \mathrm{bc} * *$ & $87.1 b^{* * *}$ & 35 & $17.1 \mathrm{bc} * *$ & $8.6 \mathrm{bc}^{* *}$ \\
\hline & $X^{2,} d f=3$ & & 21.16 & 19.94 & & 20.24 & 25.21 \\
\hline & $p$-value & & $* *$ & $* *$ & & $* *$ & $* *$ \\
\hline
\end{tabular}

Before cryopreservation, the dissected buds (1-3 mm) were incubated 10 days on MS media with 0,2 or $4 \mathrm{mg} / \mathrm{l} \mathrm{ABA}$ (Treatments 2-4). For comparison, freshly disseiscted buds without 10-day pre-treatment were included (Treatment 1)

+LN, cryopreserved, -LN, non-cryopreserved control, ABA, the concentration of abscisic acid, “-” no pretreatment $\mathrm{n}$, the number of buds in each treatment

$\chi^{2}$-value represents the result of Chi squared test of independence $(\mathrm{df}=3)$ at $0.95\left(^{*}\right)$ and $0.99(* *)$ level within each column for $-\mathrm{LN}$ and $+\mathrm{LN}$ separately. Significant differences are marked with asterisks at 0.95 (*) and $0.99\left(^{* *}\right)$ level for $-\mathrm{LN}$ and $+\mathrm{LN}$ treatments. The letters followed by asterisks denote significant differences according to pairwise comparisons (Chi squared test of equal proportions with Holm correction for p-value)

\section{The effect of pretreatment}

Pretreatment with or without ABA had a significant effect in both control and cryopreserved $R$. humulifolius buds. However, the effect of pretreatment differed between non-cryopreserved control buds and cryopreserved ones.

For non-cryopreserved controls, all three pre-treatments $(0,2$ or $4 \mathrm{mg} / \mathrm{l} \mathrm{ABA})$ had positive effect on both survival and regeneration. The survival percentage of freshly dissected buds was $61.2 \%$ while the 10 -day pre-treatment without ABA $(0 \mathrm{mg} / \mathrm{l})$ increased survival to $84.8 \%$. In the presence of 2 or $4 \mathrm{mg} / \mathrm{l} \mathrm{ABA}$ the survival percentages reached to $93.5 \%$ and $96.8 \%$ (Table 2), respectively. The same phenomenon was observed for regeneration percentagesthe regeneration of control buds without pretreatment was $51.0 \%$ while after the 10-day pretreatment without $\mathrm{ABA}$ the regeneration increased to $75.8 \%$ whereas with 2 or $4 \mathrm{mg} / \mathrm{l} \mathrm{ABA}$ the regeneration reached 90.3 and $87.1 \%$, respectively (Table 2).

In the case of cryopreserved buds, the effect of the 10-day pretreatment with 0,2 or $4 \mathrm{mg} / \mathrm{l} \mathrm{ABA}$ had a negative effect on recovery after cryopreservation. The survival percentage of freshly dissected buds was $62 \%$ while the 10-day pretreatment without ABA (0 mg/l) decreased the survival percentage to $47.1 \%$. The effect was more severe when ABA was included-only 17.6 and $17.1 \%$ of buds survived from 2 and $4 \mathrm{mg} / \mathrm{l} \mathrm{ABA}$ pretreatments (Table 2), respectively.

The regeneration percentages of ABA-treated buds were even lower. For freshly dissected buds, the regeneration percentage was 52.0 while after 10-day post-dissection incubation on ABA-free medium the regeneration percentage was $35 \%$. In the presence of 2 or $4 \mathrm{mg} / \mathrm{l} \mathrm{ABA}$, only 5.9 and $8.6 \%$ of buds regenerated after thawing (Table 2), respectively. 


\section{Transfer from in vitro to ex vitro}

Eight of the 19 rooted shoots transferred from in vitro to in vivo soil conditions survived throughout the first summer. These eight plants overwintered successfully in unheated greenhouse and were healthy and growing after 1 year of transfer (Fig. 1f).

\section{Discussion}

In the present study, $R$. humulifolius, critically endangered native plant in the wild in Finland, has been successfully cryopreserved to enable the long-term conservation of the species.

Cryopreservation protocol for germplasm conservation of $R$. humulifolius has not been reported before. However, genus Rubus includes several economically important berry species, and therefore several cryopreservation protocols including controlled rate cooling, encapsulation-dehydration, encapsulation-vitrification, PVS2-vitrification and droplet vitrification have been applied for several species in this genus (Reed 1993; Chang and Reed 1999; Vysotskaya et al. 1999; Wang et al. 2005; Gupta and Reed 2006; Ukhatova et al. 2017). For Finnish raspberry (Rubus idaeus) cultivars, an encapsulation-vitrification protocol has been developed (Wang et al. 2005). Therefore, for the native endangered $R$. humulifolius genotype, the encapsulation-vitrification protocol was used as a reference for development of the droplet vitrification protocol successfully applied in the present study resulting high survival and regeneration percentages $(62 \%$ and $52 \%$, respectively, Table 2 , Treatment 1).

The addition of ABA to growth media before cryopreservation has previously been proposed to further increase the survival percentage of cryopreserved buds and therefore it has been applied in many cryopreservation protocols of different plant species. For example, for adventitious shoots of Begonia x erythrophylla, a 7-day pre-growth period on 1.9 or 3.8 $\mu \mathrm{M}$ ABA before dissecting the shoots for cryopreservation, significantly increased the shoot regrowth from 24 to $35 \%$ or $43 \%$, respectively (Burritt 2008) while $7.6 \mu \mathrm{M}$ ABA resulted in $20 \%$ regrowth. Similarly, when in vitro shoots of pear (Pyrus cordata) were pre-cultured on culture media with 50,75 and $150 \mu \mathrm{M}$ ABA for 3 weeks before bud dissection and cryopreservation, a significant increase in regrowth from 0 to $7 \%, 10 \%$ or $18 \%$, respectively, was observed (Chang and Reed 2001). Survival of Vanda pumila was also significantly increased when shoot primordia were cultivated for 3-6 days on media including ABA $(1.0 \mathrm{mg} / \mathrm{l})(\mathrm{Na}$ and Kondo 1996). Therefore, in the present study prior to cryopreservation, dissected buds were pretreated for 10 days on media with 0,2 or $4 \mathrm{mg} / \mathrm{l} \mathrm{ABA}$.

According to our results, pre-treatment with ABA has a divergent effect on control and cryopreserved buds on $R$. humulifolius (Table 2). The same divergent effect of ABA pretreatment has been observed for in vitro sugar beet (Beta vulgaris) shoot tips in which the survival of control buds increased in the presence of ABA from 57 to $70 \%$ after 1 week of ABA pre-treatment. Contradictory, $37 \%$ of cryopreserved shoot tips survived cryopreservation without ABA treatment and with 1-week ABA treatment survival decreased from 37 to $23 \%$ (Vandenbussche and Proft 1998).

For several species, cold acclimation is needed to support ABA treatment. For example, five Rubus genotypes (three blackberry and two raspberry cultivars), ABA had no effect on recovery at room temperature whereas cold acclimation significantly increased the recovery percentages. Moreover, for some genotypes, cold together with ABA synergistically 
increased the recovery (Reed 1993). For example, for pear ( $P$. cordata), ABA treatment alone produced $18 \%$ regrowth whereas the highest post-cryopreservation regeneration $(>70 \%)$ was obtained when a 2-week cold treatment was combined with increment of $50 \mu \mathrm{M}$ ABA in the pre-treatment medium. Moreover, the presence of ABA significantly decreased the time of cold pretreatment needed for successful recovery after cryopreservation (Chang and Reed 2001). For Beta vulgaris, synergistic effect of cold and ABA treatment was also observed-ABA alone increased survival from 23 to $45 \%$ whereas under cold and ABA combination survival increased to $70 \%$ after freezing (Vandenbussche and Proft 1998). Thus, for future studies, a cold pretreatment could also be included in the protocol to see whether it could improve post-cryopreservation recovery of $R$. humulifolius.

In vitro cultivation interval as well as time from original initiation of in vitro cultures are known to affect cryopreservation outcome. For example, the survival of young (22 months from initiation) in vitro cultures of silver birch (Betula pendula) was significantly higher (37.5\%) than that from 55 months old cultures (14.8\%) (Ryynänen and Häggman 2001). In the case of Dianthus caryophyllus, the survival of shoot tips increased with the time from last subculture reaching $21 \%$ after 3 days, $94 \%$ after 14 days and $98 \%$ after 3 weeks and 2 months of the last subculture (Dereuddre et al. 1988).

In the present study, the best recovery after cryopreservation of $R$. humulifolius in vitro buds was achieved when 1-month-old cultures (from the last subculture) without any pretreatment were used. In detail, the optimal cryopreservation procedure in the present study was following. (1) Preculture on $1 / 2 \mathrm{MS}$ medium with $0.1 \mathrm{mg} / \mathrm{l} \mathrm{BAP,} 0.05 \mathrm{mg} / \mathrm{l} \mathrm{NAA}$, $100 \mathrm{mg} / \mathrm{l}$ myo-inositol including $0.25,0.5$ and $0.75 \mathrm{M}$ sucrose for 1 day per concentration. (2) Osmoprotection (loading) in $0.75 \mathrm{M}$ sucrose, $2 \mathrm{M}$ glycerol in $1 / 2 \mathrm{MS}$ for $90 \mathrm{~min}$. (3) Vitrification in plant vitrification solution 2 (PVS2: $30 \%$ glycerol, 15\% ethylene glycol, $15 \%$ DMSO, $0.4 \mathrm{M}$ sucrose in $1 / 2 \mathrm{MS}$ ) for $3 \mathrm{~h}$ followed by transfer of the buds to aluminum foil pieces $(0.5 \times 1.5 \mathrm{~cm})$ with $2-3 \mu \mathrm{l}$ droplets of PVS2. (4) Cooling: The quick transfer of foils with buds into cryotubes filled with liquid nitrogen (LN) and storage in LN container $-196{ }^{\circ} \mathrm{C}$ for at least $1 \mathrm{~h}$. (5) Rewarming: Immersion of the cryotubes at $40{ }^{\circ} \mathrm{C}$ water bath for $3 \mathrm{~min}$. (6) Dilution: Transfer of foils with buds to $30 \mathrm{ml}$ unloading solution (1 M sucrose in $1 / 2 \mathrm{MS}$ ) at RT. (7) Regeneration: The removal of excess moisture by filter paper and cultivation on $1 / 2 \mathrm{MS}$ medium with $0.1 \mathrm{mg} / \mathrm{l} \mathrm{BAP,} 0.05 \mathrm{mg} / \mathrm{l} \mathrm{NAA}, 100 \mathrm{mg} / \mathrm{l}$ myoinositol and $30 \mathrm{~g} / \mathrm{l}$ sucrose on Petri plates for 4 days in dark before transfer to light in the culture room.

There are no previous cryopreservation experiments for $R$. humulifolius. However, the results can be compared to the ones obtained for other species of the same genus. Gupta and Reed (2006) reported 96-100\% survival and 45-78\% regrowth of four Rubus (blackberry and raspberry) genotypes after cryopreservation by PVS2 vitrification. Correspondingly Wang et al. (2005) reported 46-90\% survival and 50-85\% regrowth after cryopreservation of 7 raspberry (Rubus idaeus) genotypes. Recently, Ukhatova et al. (2017) reported $85-100 \%$ survival and $24-89 \%$ regeneration of 12 red raspberry cultivars. Thus, the present results, $61 \%$ survival and $51 \%$ regeneration after LN exposure, are in line with the ones presented so far for the species of genus Rubus. Actually, the survival and regeneration of freshly dissected control buds ( $-\mathrm{LN}$, treated with all the solutions except freezing in $\mathrm{LN}$ ) were the same as cryopreserved ones (62\% survival and 52\% regeneration) (Treatment 1 in Table 2) showing that all the shoot tips that survived cryopreservation treatments could withstand freezing in LN. Therefore, in future, it could be tested whether different incubation times in loading solution and PVS2 could affect the survival and regeneration of both control and cryopreserved buds of $R$. humulifolius. 
At present, cryopreserved $R$. humulifolius in vitro buds are safely conserved in the cryofacility and the in vitro plants are maintained in the tissue culture facility of Botanical Gardens at the University of Oulu, Finland. Moreover, the success of the cryopreservation has allowed the transfer of the cryopreserved plants from in vitro to in vivo conditions. Thus the existing material in cryo-facility, in the greenhouse and in outdoor garden allow additional reintroductions of the species in the future. In order to protect threatened plant species, including $R$. humulifolius, it is important to combine both ex situ and in situ conservation tools. To address the unpredictable effects of climate change, ex situ plant storages, including storage in LN, play an important role in the conservation of biodiversity (Liu et al. 2018). Cryopreservation is a beneficial conservation method for several reasons, the main ones arguably being the reduced risk of microbial contamination and reduced costs ( $\mathrm{Li}$ and Pritchard 2009). In comparison to in vitro culture, cryopreservation reduces the risk of genetic instability related to prolonged in vitro culture (Dulloo et al. 2010). The minimum space and maintenance requirements make cryopreservation an essential tool for the long-term storage of plant material. The fact that $R$. humulifolius has become extinct in its native growing areas in Finland is yet another example of the irreversible effects of human activity. Reintroduction of $R$. humulifolius has also been difficult because of increased human activity land use for construction in the area and in the suitable nearby areas (Kypärä 2012). Reintroduction of threatened species into their native environments is challenging (Sarrazin and Barbault 1996). Increased land use activity, as in the case of $R$. humulifolius, is often combined with other habitat deterioration under changing climate. Finnish $R$. humulifolius is an example of rather unique case where the whole population would have gone extinct without ex situ conservation tools. Developing cryogenic protocol, which was carried out in this study, is additional tool to ex situ conservation toolbox and helps to maintain the plant both in ex situ and in situ repositories in the future. To conclude, the ex situ conservation of plant species e.g. in botanical gardens and in tissue culture facilities as well as in cryogenic tanks continues to be an important tool in maintaining biodiversity also in the future (Reed 2017; Liu et al. 2018).

Acknowledgements Open access funding provided by University of Oulu including Oulu University Hospital. Our sincere thanks to Aino Hämäläinen, Sirpa Lehtola, Tuomas Kauppila (from Botanical Gardens, University of Oulu, Finland) and Taina Uusitalo (Ecology and Genetics Unit, University of Oulu, Finland) for taking care of the plant material. The study was partly funded by LIFE+ 2011 (BIO/FI/917 ESCAPE).

\section{Compliance with ethical standards}

Conflict of interest The authors declared that they have no conflict of interest.

Open Access This article is distributed under the terms of the Creative Commons Attribution 4.0 International License (http://creativecommons.org/licenses/by/4.0/), which permits unrestricted use, distribution, and reproduction in any medium, provided you give appropriate credit to the original author(s) and the source, provide a link to the Creative Commons license, and indicate if changes were made.

\section{References}

Alkemade R, Bakkenes M, Eickhout B (2011) Towards a general relationship between climate change and biodiversity: an example for plant species in Europe. Reg Environ Change 11:S143-S150

Benelli C, Carlo A, Engelmann F (2013) Recent advances in the cryopreservation of shoot-derived germplasm of economically important fruit trees of Actinidia, Diospyros, Malus, Olea, Prunus, Pyrus and Vitis. Biotechnol Adv 31:175-185 
Benson E (2008) Cryopreservation theory. In: Reed B (ed) Plant cryopreservation: a practical guide. Springer, New York, pp 15-32

Burritt DJ (2008) Efficient cryopreservation of adventitious shoots of Begonia $\times$ erythrophylla using encapsulation-dehydration requires pretreatment with both ABA and proline. Plant Cell Tissue Organ Cult 95:209-215

Chang Y, Reed BM (1999) Extended cold acclimation and recovery medium alteration improve regrowth of Rubus shoot tips following cryopreservation. CryoLetters 20:371-376

Chang Y, Reed BM (2001) Preculture conditions influence cold hardiness and regrowth of Pyrus cordata shoot tips after cryopreservation. Hortscience 36:1329-1333

Dereuddre J, Fabre J, Bassaglia C (1988) Resistance to freezing in liquid nitrogen of carnation (Dianthus caryophyllus L. var Eolo) apical and axillary shoot tips excised from different aged in vitro plantlets. Plant Cell Rep 7:170-173

Dulloo ME, Hunter D, Borelli T (2010) Ex situ and in situ conservation of agricultural biodiversity: major advances and research needs. Not Bot Horti Agrobo 38:123-135

Engelmann F (2004) Plant cryopreservation: progress and prospects. In vitro Cell Dev Biol Plant 40:427-433

Feehan J, Harley M, van Minnen J (2009) Climate change in Europe. 1. Impact on terrestrial ecosystems and biodiversity: a review. J Agron Sustain Dev 29:409-421

Gupta S, Reed BM (2006) Cryopreservation of shoot tips of blackberry and raspberry by encapsulationdehydration and vitrification. CryoLetters 27:29-42

Hannah L, Midgley GF, Lovejoy T, Bond WJ, Bush M, Lovett JC, Scott D, Woodward FI (2002) Conservation of biodiversity in a changing climate. Conserv Biol 16:264-268

Hawkes JG, Maxted N, Ford-Lloyd BV (2012) The ex situ conservation of plant genetic resources. Springer, the Netherlands

Heywood VH, Dulloo ME (2005) In situ conservation of wild plant species: a critical global review of good practices. IPGRI, Rome

Hooper DU, Adair EC, Cardinale BJ, Byrnes JEK, Hungate BA, Matulich KL, Gonzales A, Duffy JE, Gamfeldt L, O'Connor MJ (2012) A global synthesis reveals biodiversity loss as a major driver of ecosystem change. Nature 486:105-108

Hyvärinen E, Juslén A, Kemppainen E, Uddström A, Liukko UM (2019) The 2019 red list of Finnish species. Ympäristöministeriö \& Suomen ympäristökeskus, Helsinki

Jenderek M, Reed B (2017) Cryopreserved storage of conal germplasm in the USDA National Plant Germplasm System. In Vitro Cell Dev Biol Plant. https://doi.org/10.1007/s11627-017-9828-3

Kypärä T (2012) Siperianlillukka-sibiriskt junfrubär, Rubus humulifolius (Rosaceae). In: Ryttäri T, Kalliovirta M, Lampinen R (eds) Suomen uhanalaiset kasvit. Tammi, Helsinki, pp 285-287 (In Finnish)

Li DZ, Pritchard HW (2009) The science and economics of ex situ plant conservation. Trends Plant Sci 14:614-621

Lindner M, Maroschek M, Netherer S, Kremer A, Barbati A, Garcia-Gonzalo J, Seidl R, Delzon S, Corona P, Kolström Lexer MJ, Marchetti M (2010) Climate change impacts, adaptive capacity, and vulnerability of European forest ecosystems. For Ecol Manag 259:698-709

Liu U, Breman E, Cossu TA, Kenny S (2018) The conservation value of germplasm stored at the millennium seed bank, royal botanic gardens, Kew, UK. Biodivers Conserv. https://doi.org/10.1007/s1053 1-018-1497-y

Mantyka-Pringle CS, Martin TG, Rhodes JR (2012) Interactions between climate and habitat loss effects on biodiversity: a systematic review and meta-analysis. Glob Change Biol 18:1239-1252

Matsumoto T (2017) Cryopreservation of plant genetic resources: conventional and new methods. Rev Agric Sci 5:13-20

Matsumoto T, Niino T (2014) The development of plant vitrification solution 2 and recent PVS2-based vitrification protocols. In: Reed BM (ed) Proceedings of the second international symposium on plant cryopreservation. Acta Horticulturae 1039:21-28

Mikkola E (1927) Rubus humulifolius löydetty Jyväskylästä. Luonnon Ystävä 31:23-27 (In Finnish)

Murashige T, Skoog F (1962) A revised medium for rapid growth and bioassays with tobacco tissue cultures. Plant Physiol 15:493-497

$\mathrm{Na} \mathrm{H}$, Kondo K (1996) Cryopreservation of tissue-cultured shoot primordia from shoot apices of cultured protocorms in Vanda pumila following ABA preculture and desiccation. Plant Sci 118:195-201

R Core Team (2012) R: A language and environment for statistical computing. R Foundation for Statistical Computing, Vienna, Austria. R version 2.15.1 (2012-06-22)

Rassi P, Hyvärinen E, Juslén A, Mannerkoski I (2010) The Red List of Finnish species. Ministry of the Environment and Finnish Environment Institute, Helsinki 
Reed BM (1993) Responses to ABA and cold acclimation are genotype dependent for cryopreserved blackberry and raspberry meristems. Cryobiology 30:179-184

Reed B (2008) Plant cryopreservation: a practical guide. Springer, New York

Reed BM (2017) Plant cryopreservation: a continuing requirement for food and ecosystem security. In Vitro Cell Dev Biol Plant 53:285-288

Ryynänen L, Häggman H (2001) Recovery of cryopreserved silver birch shoot tips is affected by the prefreezing age of the cultures and ammonium substitution. Plant Cell Rep 20:354-360

Sakai A, Hirai D, Niino T (2008) Development of PVS-based vitrification and encapsulation-vitrification protocols. In: Reed BM (ed) Plant cryopreservation: a practical guide. Springer, New York, NY

Sarrazin F, Barbault R (1996) Reintroduction: challenges and lessons for basic ecology. Trends Ecol Evol 11:474-478

Skirvin RM, Motoike S, Coyner M, Norton MA (2005) Rubus spp. cane fruit. In: Litz RE (ed) Biotechnology of fruit and nut crops biotechnology in agriculture series no 29. CABI Publishing, Wallingford, pp 566-580

Thomas CD, Cameron A, Green RE, Bakkenes M, Beaumont LJ et al (2004) Extinction risk from climate change. Nature 427:145-148

Ukhatova YV, Dunaeva SE, Antonova OY, Apalikova OV, Pozdnaikova KS, Novikova LY, Shuvalova LE, Gavrilenko TA (2017) Cryopreservation of red raspberry cultivars from the VIR in vitro collection using a modified droplet vitrification method. In Vitro Cell Dev Biol Plant 53:394-401

Vandenbussche B, De Proft MP (1998) Cryopreservation of in vitro sugar beet shoot tips using the encapsulation-dehydration technique: influence of abscisic acid and cold acclimation. Plant Cell Rep 17:791-793

Vellend M, Baeten L, Becker-Scarpitta A, Boucher-Lalonde V, McCune JL, Messier J, Myers-Smith IH, Sax DF (2017) Plant biodiversity change across scales during the anthropocene. Annu Rev Plant Biol 68(1):563-586

Vysotskaya ON, Mochammed AI, Butenko RG (1999) Cryopreservation of red raspberry meristems (Rubus idaeus $\mathrm{L}$.) isolated from in vitro plantlets. Biol Bull 26:19-22

Wang Q, Laamanen J, Uosukainen M, Valkonen JPT (2005) Cryopreservation of in vitro-grown shoot tips of raspberry (Rubus idaeus L.) by encapsulation vitrification and encapsulation dehydration. Plant Cell Rep 24:280-288

Publisher's Note Springer Nature remains neutral with regard to jurisdictional claims in published maps and institutional affiliations. 